\title{
Predictors of Mortality in a Clinic Cohort of HIV-1 Infected Children Initiated on Antiretroviral Therapy in Jos, Nigeria
}

Augustine O Ebonyi ${ }^{1}$, Stephen Oguche ${ }^{1}$, Seema T Meloni ${ }^{2}$, Solomon A Sagay ${ }^{3}$, Demetrios N Kyriacou ${ }^{4}$, Chad J Achenbach ${ }^{5}$, Oche O Agbaji ${ }^{6}$, Tinuade A Oyebode $^{3}$, Prosper Okonkwo ${ }^{7}$, John A Idoko ${ }^{8}$ and Phyllis J Kanki ${ }^{2^{*}}$

${ }^{1}$ Department of Paediatrics, University of Jos/ Jos University Teaching Hospital, Jos, Nigeria

${ }^{2}$ Department of Immunology and Infectious Diseases, Harvard School of Public Health, Boston, MA, USA

${ }^{3}$ Department of Obstetrics and Gynaecology, University of Jos/ Jos University Teaching Hospital, Jos, Nigeria

${ }^{4}$ Department of Emergency Medicine, Northwestern University Feinberg School of Medicine, Northwestern University, Chicago, Illinois, USA

${ }^{5}$ Division of Infectious Diseases and Center for Global Health, Northwestern University Feinberg

School of Medicine, Northwestern University, Chicago, Illinois, USA

${ }^{6}$ Department of Medicine, University of Jos/ Jos University Teaching Hospital, Jos, Nigeria

${ }^{7}$ AIDS Prevention Initiative in Nigeria (APIN) LLC, Abuja, Nigeria

${ }^{8}$ National Agency for the Control of AIDS (NACA), Abuja, Nigeria

*Corresponding author: Phyllis Kanki, Department of Immunology and Infectious Diseases, Harvard School of Public Health, 651 Huntington Avenue, Boston, MA, USA, Tel: 6174321267; E-mail: pkanki@hsph.harvard.edu

Received date: October 28, 2014; Accepted date: December 16, 2014; Published date: December 20, 2014

Copyright: ( 2014 Ebonyi AO, et al. This is an open-access article distributed under the terms of the Creative Commons Attribution License, which permits unrestricted use, distribution, and reproduction in any medium, provided the original author and source are credited.

\section{Abstract}

Background: Mortality among human immunodeficiency virus-1 (HIV-1) infected children initiated on antiretroviral therapy (ART) though on a decline still remains high in resource-limited countries (RLC). Identifying baseline factors that predict mortality could allow their possible modification in order to improve pediatric HIV care and reduce mortality.

Methods: We conducted a retrospective cohort study analyzing data on 691 children, aged 2 months-15 years, diagnosed with HIV-1 infection and initiated on ART between July 2005 and March 2013 at the pediatric HIV clinic of Jos University Teaching Hospital. Lost to follow-up children were excluded from the analyses. A multivariate Cox proportional hazards model was fitted to identify predictors of mortality.

Results: Median follow-up time for the 691 children initiated on ART was 4.4 years (interquartile range (IQR), 1.8-5.9) and at the end of 2752 person-years of follow-up, $32(4.6 \%)$ had died and $659(95.4 \%)$ survived. The mortality rate was 1.0 per 100 child-years of follow-up period. The median age of those who died was about two times lower than that of survivors [1.7 years (IQR, 0.6-3.6) versus 3.9 years (IQR, 3.9-10.3), p<0.001]. On unadjusted Cox regression, the risk of dying was about three and half times more in children $<5$ years of age compared to those $>5$ years $(p=0.02)$ Multivariate modeling identified age as the main predictor of death with mortality decreasing by $24 \%$ for every 1 year increase in age (Adjusted Hazard Ratio (AHR) $=0.76$ [0.62-0.94], $\mathrm{p}=0.013$.

Conclusion: The lower mortality rate for our study suggests that even in RLC, mortality rates could be reduced given a good standard of care. Early initiation of ART in younger children with close monitoring during follow-up could further reduce mortality.

Keywords: HIV-1; Mortality; Severe immunodeficiency; ART; Children

\section{Introduction}

There were 35.3 million people living with the Human Immunodeficiency Virus (HIV) infection globally in 2012 with the majority in sub-Saharan Africa (SSA) [1]; of those, 2.9 million are children living in SSA [2]. There has been a steady decline in HIVrelated deaths globally and this has been attributed to the scaling-up of Antiretroviral Therapy (ART), with deaths in children estimated at 210,000 in 2012 [1].
Despite this decline, the proportion of deaths remains higher in resource-limited countries (RLC) [3-10] compared to resource-rich countries (RRC) [11-13]. A recent systematic review reported an approximate 10-fold difference in mortality between children in RLC versus RRC after ART initiation, with a mean mortality rate of 8.0 in RLC versus 0.9 deaths per 100 child-years in RRC. Studies in Africa on HIV-related mortality are complex due to other significant non-HIV causes of mortality [3-9]. The mortality rates in these studies ranged from 4.0 deaths per 100 child-years in Ethiopia [4] to 8.4 deaths per 100 child-years in Kenya [3]. Similar studies from Nigeria are lacking. Identification of baseline factors that predict mortality could allow for their possible modification in order to improve pediatric HIV care and reduce HIV-related mortality in RLC. 
In this study, we determined the mortality rate and predictors of mortality in HIV-1 infected children initiated on ART attending the paediatric HIV clinic of the Jos University Teaching Hospital (JUTH) in Plateau State, Nigeria.

\section{Methods}

\section{Study design}

This was a retrospective cohort study, analyzing data on 691 consecutive HIV-1 infected children initiated on ART between July 2005 and March 2013.

\section{Study subjects}

This study included children aged 2 months -15 years diagnosed with HIV-1 infection at presentation to the pediatric HIV clinic and subsequently initiated on ART. Children who met the criteria for loos to follow-up (LTFU), those transferred from other HIV care facilities to our clinic and who were already on ART at time of presentation, were excluded from the analysis.

\section{Study setting}

This evaluation was conducted utilizing data from the AIDS Prevention Initiative in Nigeria (APIN)-supported pediatric HIV clinic at JUTH. This clinic provides comprehensive HIV care services for the city of Jos, which is located in the Jos North Local Government Area (LGA) of Plateau State. The 2006 national census puts the population of the state at about 3,206,531 with the state capital having a population of approximately $900,000[14,15]$. The clinic serves as a referral center for both health facilities in the other LGAs of the state and neighboring states in the country. During the study period, APIN was supported by the U.S. Department of Health and Human Services, Health Resources and Services Administration in collaboration with the Harvard School of Public Health, through a PEPFAR grant.

\section{Patient care and management}

The diagnosis of HIV and the criteria for initiating ART in children were based on the 2010 Nigerian National Guidelines for Paediatric HIV and AIDS Treatment and Care [16]; prior to the adoption of the 2010 Nigerian Guidelines, which recommends that all HIV-infected children $<24$ months of age should be started on ART, there were two previous WHO guidelines (the 2006 guidelines, which used $\mathrm{CD} 4^{+}$ count or CD4\% levels for determining when to start ART, and the 2008 guidelines, which recommended that all children $<12$ months of age should be started on ART irrespective of their $\mathrm{CD} 4^{+}$count or CD4\% levels) that covered patients included in this evaluation. For HIV serodiagnosis, children aged 18 months and above had two different rapid HIV tests - Uni-Gold (Trinity Biotech Plc Bray Co.; Wicklow, Ireland) and Determine (Determine Alere Medical Co. Ltd.; Matsuhidai, Japan) HIV-1/2 tests. For those under 18 months of age, the Amplicor HIV-1 DNA PCR test, version 1.5 (Roche Molecular Systems; Branchburg, NJ, USA) was used for diagnosing HIV infection.

For most patients, ART is started within 2 to 4 weeks of HIV diagnosis. For this cohort, the ART regimen most commonly used was zidovudine (AZT)+lamivudine (3TC)+nevirapine (NVP); however, if the patient was diagnosed with PTB at the time of ART initiation, NVP was replaced with efavirenz (EFV) in the regimen. From the time of HIV diagnosis or ART initiation, the children were monitored, initially every 1 or 2 weeks for one month then at 4 -week intervals thereafter. The diagnosis of PTB at the time of presentation was based on the 2010 Nigerian National Tuberculosis and Leprosy Control Programme guidelines [17], which include clinical and radiological features, history of TB contact and Mantoux test for children with HIV.

All children had laboratory tests performed as part of routine clinical care. Laboratory evaluations of the patients was done every 6 months to monitor adherence and adverse drug reactions; tests included: viral load enumeration, $\mathrm{CD}^{+}$count, full blood count (hemoglobin/packed cell volume levels and white cell counts), blood chemistry (liver function tests and serum creatinine level). The $\mathrm{CD} 4^{+}$ lymphocyte count was measured using Flow cytometry (Partec $\mathrm{GmbH}$, Munster Germany) and HIV-1 RNA viral load was measured using Roche Cobas Amplicor HIV-1 Monitor, version 1.5 (Roche Diagnostics GmbH, Mannheim, Germany) with a limit of detection at 400 copies/ml.

Patients and their caregivers received continuous adherence Counseling during each clinic follow-up visit. Adherence Counseling was done by trained nurses and adherence counselors, who themselves were trained by professional adherence counselors from the Harvard School of Public Health. Also, to enhance adherence, patients and their caregivers were taught how to use alarm clocks daily for reminding them of when the next ARV dose is due.

Patients were promptly treated for any identified intercurrent infections, including opportunistic infection (OIs). They were also managed for any associated malnutrition and this includes the use of 'plumpy nuts' in some cases and nutrition education. The caregivers were encouraged to be part of the HIV support group.

\section{Source of data}

All patient clinical data were maintained on-site in electronic databases; data were entered into electronic medical records systems (EMRS) from paper-based records that were completed at the point of care. For these analyses, we abstracted all patient data from the EMRS.

The baseline data were obtained near time of ART initiation and included the following.

Variables: demographic (age, sex), clinical (height, weight, WHO HIV clinical stage, oral thrush, diagnosis of pulmonary tuberculosis (PTB), commencement of cotrimoxazole (CTX) for OI prophylaxis and deaths) and laboratory (hemoglobin $(\mathrm{Hb})$ level, viral load and absolute $\mathrm{CD}^{+}$cell count). We determined Z-scores, adjusted for age and sex, from the weight and height of the study subjects, using the WHO AnthroPlus software [18]. The Z-scores were then categorized into a binary variable using the WHO cut-off of $Z<-3$ for severe malnutrition (weight-for-age (WAZ)-3) [19]. Severe immunodeficiency was determined using the absolute $\mathrm{CD} 4^{+}$cell count as recommended by the WHO [20], which included: $<1500 / \mathrm{mm}^{3}$ for children $<11$ months, $<750 / \mathrm{mm}^{3}$ for those $12-35$ months, $<350 / \mathrm{mm}^{3}$ for those 36-59 months and $<200 / \mathrm{mm}^{3}$ for those $>5$ years. Hemoglobin from whole blood counts was also categorized into a binary variable using the WHO cut-off of $\mathrm{Hb}<8 \mathrm{~g} / \mathrm{dL}$ for designation of anemia [21]. 
Citation: Ebonyi AO, Oguche S, Meloni ST, Sagay SA, Kyriacou DN, et al. (2014) Predictors of Mortality in a Clinic Cohort of HIV-1 Infected Children Initiated on Antiretroviral Therapy in Jos, Nigeria. J AIDS Clin Res 5: 403. doi:0.4172/2155-6113.1000403

Page 3 of 7

\section{Outcome variable}

The outcome was death from HIV-related causes, ARV drug toxicity, or unknown causes. The cause of death was ascertained using hospital records or by means of a verbal autopsy from family members. Children who transferred to another facility or voluntarily withdrew from care were considered as LTFU and were excluded from the analyses since their outcomes were not know. Each child was followed from the time they initiated ART until death or the end of study period (31 $1^{\text {st }}$ December 2013).

\section{Statistical analysis}

The associations between each independent variable and death was examined using the Chi squared or Fisher's exact test for categorical variables and the Wilcoxon-Mann-Whitney test for continuous variables. Kaplan-Meier survival methods were used to estimate the cumulative probability of death and the survival curves were compared between groups using the log-rank test. Unadjusted Cox proportional hazards regression modeling was used to examine the association between the independent variables and death. Variables that were associated with death in the unadjusted Cox regression at $\mathrm{p}<0.20$ were fit into a multivariate Cox regression model. A forward step-wise modeling strategy was used where variables with $\mathrm{p}<0.05$ remained in the model and those with $p>0.10$ exited the model, at each step of the modeling process. Results were expressed as Hazard Ratios (HRs) with their 95\% confidence intervals (CIs). All analyses were performed using Stata software version 10.0 (Stata Corporation, College Station, Texas, USA) and all tests were two-sided with a p-value of $<0.05$ considered statistically significant.

To test for the potential impact of those that were excluded, we repeated our multivariate modeling treating those that were excluded as having died.

\section{Ethical approval}

The parents/guardians of the children provided written informed consent for secondary use of data for research which was approved by the Ethics Committee of the Jos University Teaching Hospital, AIDS Prevention Initiative in Nigeria, Ltd./Gte (APIN) and the Institutional Review Board (IRB) at the Harvard School of Public Health.

\section{Results}

\section{Baseline characteristics}

Between 2005-2013, 941 children were diagnosed with HIV-1 infection at the Jos University Teaching Hospital. Of those patients, 744 (73.4\%) initiated ART. For this analysis, we excluded 53 (5.6\%) patients that, either transferred, withdrew or were LTFU. Among those initiated on ART, the median age was 3.7 years (IQR, 1.8-6.9), with $353(51.1 \%)$ being males and the median follow-up time since initiation of ART was 4.4 years (IQR, 1.8-5.9). The total study time contributed by the study participants was 2752 person-years. There were 51 (7.4\%) children with PTB, 24 (3.5\%) with oral thrush, 284 (41.1\%) with WHO clinical stage 3 or 4,574 (83.1\%) receiving CTX prophylaxis prior to commencing ART, 147 (21.3\%) with severe malnutrition, $34(4.9 \%)$ with anemia and $283(41 \%)$ with severe immunodeficiency at ART initiation. The median baseline CD4+ cell count and CD4\% were 480 cells/ $\mu$ (IQR, 249-810) and 17 (IQR, 10-26) respectively, while the HIV RNA log viral load was $10.7 \log 10$ copies/ $\mathrm{ml}$ (IQR, 8.9-12.2) (Table 1).The majority of those meeting the WHO $\mathrm{CD} 4{ }^{+}$cell count criteria for severe immunodeficiency were $<5$ years of age $(199,70.3 \%)$.

\begin{tabular}{|c|c|c|c|c|}
\hline Characteristics & Total & $\begin{array}{l}\text { Children who } \\
\text { Died }\end{array}$ & $\begin{array}{l}\text { Children who } \\
\text { survived }\end{array}$ & $P$ value \\
\hline \multicolumn{5}{|l|}{ Age (years) } \\
\hline$<1$ & $85(12.3)$ & $12(37.5)$ & $73(11.1)$ & $<0.001$ \\
\hline $1-5$ & $353(51.1)$ & $15(46.9)$ & $338(51.3)$ & \\
\hline $6-10$ & $179(25.9)$ & $5(15.6)$ & $174(26.4)$ & \\
\hline$>10$ & $74(10.7)$ & $0(0)$ & $74(11.2)$ & \\
\hline Median (IQR) & $3.7(1.8,6.9)$ & $1.7(0.6,3.6)$ & $3.9(1.8,10.3)$ & $<0.001$ \\
\hline \multicolumn{5}{|l|}{ Sex } \\
\hline Male & $353(51.1)$ & $22(68.8)$ & $331(50.2)$ & 0.03 \\
\hline Female & $338(48.9)$ & $10(31.2)$ & $328(49.8)$ & \\
\hline \multicolumn{5}{|c|}{ Follow-up time (years) } \\
\hline Median (IQR) & $4.4(1.8,5.9)$ & $0.1(0.03,0.5)$ & $4.7(2.2,6.0)$ & $<0.001$ \\
\hline \multicolumn{5}{|l|}{ Pulmonary TB } \\
\hline Yes & $51(7.4)$ & $5(15.6)$ & $46(7.0)$ & 0.07 \\
\hline No & $640(92.6)$ & $27(84.4)$ & $613(93.0)$ & \\
\hline \multicolumn{5}{|c|}{ Cotrimoxazole prophylaxis } \\
\hline No & $117(16.9)$ & $5(15.6)$ & $112(17.0)$ & 0.84 \\
\hline Yes & $574(83.1)$ & $27(84.4)$ & $547(83.0)$ & \\
\hline \multicolumn{5}{|c|}{ WHO clinical stage } \\
\hline 3 or 4 & $284(41.1)$ & $16(50.0)$ & $268(40.7)$ & 0.41 \\
\hline 1 or 2 & $354(51.2)$ & $15(46.9)$ & $339(51.4)$ & \\
\hline Missing & $53(7.7)$ & $1(3.1)$ & $52(7.9)$ & \\
\hline \multicolumn{5}{|l|}{ Oral thrush } \\
\hline Yes & $24(3.5)$ & $2(6.0)$ & $22(3.3)$ & 0.38 \\
\hline No & $666(96.4)$ & $30(94.0)$ & $636(96.5)$ & \\
\hline Missing & $1(0.1)$ & $0(0.0)$ & $1(0.2)$ & \\
\hline \multicolumn{5}{|c|}{ Weight-for-age $Z$ score } \\
\hline$<-3.0$ & $147(21.3)$ & $12(37.5)$ & $135(20.5)$ & 0.06 \\
\hline$>-3.0$ & $466(67.4)$ & $20(62.5)$ & $446(67.7)$ & \\
\hline Median (IQR) & $\begin{array}{l}-1.8 \quad(-2.9 \\
-0.8)\end{array}$ & $-2.6(-4.0,-0.9)$ & $-1.8(-3.0,-0.8)$ & 0.1 \\
\hline Missing & $78(11.3)$ & $0(0.0)$ & $78(11.8)$ & \\
\hline \multicolumn{5}{|c|}{ Haemoglobin level (g/dl) } \\
\hline$<8$ & $34(4.9)$ & $2(6.3)$ & $32(4.9)$ & 0.61 \\
\hline$>8$ & $609(88.1)$ & $25(78.1)$ & $584(88.6)$ & \\
\hline
\end{tabular}


Citation: Ebonyi AO, Oguche S, Meloni ST, Sagay SA, Kyriacou DN, et al. (2014) Predictors of Mortality in a Clinic Cohort of HIV-1 Infected Children Initiated on Antiretroviral Therapy in Jos, Nigeria. J AIDS Clin Res 5: 403. doi:0.4172/2155-6113.1000403

Page 4 of 7

\begin{tabular}{|c|c|c|c|c|}
\hline Median (IQR) & $10(9,11)$ & $10(9,11)$ & $10(9,11)$ & 0.31 \\
\hline Missing & $48(7.0)$ & $5(15.6)$ & $43(6.5)$ & \\
\hline \multicolumn{5}{|c|}{ CD4 count (cells/ $\mu \mathrm{l})$} \\
\hline Median (IQR) & $\begin{array}{l}480 \quad(249, \\
810)\end{array}$ & $572(234,896)$ & $476(250,809)$ & 0.57 \\
\hline Missing & $55(7.9)$ & $5(15.6)$ & $50(7.6)$ & \\
\hline \multicolumn{5}{|l|}{ CD4\% } \\
\hline Median (IQR) & $17(10,26)$ & $14(10,21)$ & $17(10,26)$ & 0.49 \\
\hline Missing & $134(19.4)$ & $8(25.0)$ & $126(19.1)$ & \\
\hline \multicolumn{5}{|c|}{ Severe immunodeficiency } \\
\hline Yes & $283(41.0)$ & $16(50.0)$ & $267(40.5)$ & 0.11 \\
\hline No & $354(51.2)$ & $11(34.4)$ & $343(52.1)$ & \\
\hline Missing & $54(7.8)$ & $5(15.6)$ & $49(7.4)$ & \\
\hline \multicolumn{5}{|c|}{ HIV RNA viral load (copies/ ml) } \\
\hline Median (IQR) & $\begin{array}{l}45552(7646, \\
204188)\end{array}$ & $\begin{array}{l}170133(39203, \\
728188)\end{array}$ & $\begin{array}{l}44579 \\
(6638,201000)\end{array}$ & 0.01 \\
\hline Missing & $286(41.4)$ & $15(46.9)$ & $390(59.2)$ & \\
\hline \multicolumn{5}{|c|}{ HIV RNA Log viral load (copies/ml) } \\
\hline$>10.5$ & $218(31.5)$ & $12(37.5)$ & $206(31.3)$ & 0.04 \\
\hline$<10.5$ & $187(27.1)$ & $3(9.4)$ & $184(27.9)$ & \\
\hline Median (IQR) & $\begin{array}{l}10.7 \\
12.2)\end{array}$ & $\begin{array}{l}12.0 \\
13.5) \quad(10.6,\end{array}$ & $10.7(8.8,12.2)$ & 0.01 \\
\hline Missing & $286(41.4)$ & $17(53.1)$ & $269(40.8)$ & \\
\hline
\end{tabular}

Data are presented as No. (\%) or median (interquartile range). ${ }^{\star} \mathrm{P}$ value for Chi squared or Fisher's exact test for the association between a variable and death; and Wilcoxon-Mann-Whitney test for Table 1: Baseline characteristics of 691 HIV-1 infected children initiated on ART between 2005-2013 at the Jos University Teaching Hospital who died or survived . comparison of two medians

\section{Mortality after initiation of ART}

Of the 691children initiated on ART, 32 (4.6\%) had died by the end of the follow-up period. The overall mortality rate was 1.0 per 100 child-years of follow-up (95\% CI, 0.7-1.5). The median follow-up time of those who died was 0.1 years (IQR, 0.03-0.5) and their median age was 1.7 years (IQR, 0.6-3.6). The median age of those who died was about two times lower than that of survivors (1.7 years (IQR, 0.6-3.6) versus 3.9 years (IQR, 3.9-10.3), $\mathrm{p}<0.001$ ) (Table 1). The deaths were attributed to: HIV (23,71.9\%), ARV toxicity $(1,3.1 \%)$, other causes $(5,15.6 \%)$ and unknown causes $(3,9.4 \%)$. The majority of the deaths occurred during the first 6 months of the follow-up period (26,81.3\%); $84.4 \%$ of the deaths had occurred by 1 year of follow-up. Among the children who died, majority were male $(22,68.8 \%),<5$ years of age $(27,84.4 \%)$, had a baseline WHO clinical stage of 3 or $4(16,50.0 \%)$ and had severe immunodeficiency $(16,50 \%)$. Of the children who died, the majority of those who had severe immunodeficiency $(15,93.8 \%)$, severe malnutrition $(10,83.3 \%)$, and PTB $(5,100 \%)$ were aged $<5$ years.

Amongst those $<5$ years, more males $(66.7 \%)$ than females $(33.3 \%)$ died.

Figure 1 shows the Kaplan-Meier survival probabilities overall, by sex, age group and PTB. In unadjusted analyses, the log rank tests indicated significant associations between sex, as well as age group with mortality risk from time of initiation of ART ( $p=0.03$ and $p=0.01$ respectively).

In the unadjusted Cox regression analysis, the risk of dying was about three and half times more in children $<5$ years of age as compared to those $>5$ years $(\mathrm{p}=0.02)$, about two and half times more in males compared to females $(\mathrm{p}=0.03)$, and 2.1 times more in patients with a $W A Z<-3$ those with a WAZ $\geq-3$ (Table 2). Following multivariate Cox regression modeling age was the only variable that remained in the model as significant predictor of mortality, with the risk of dying decreasing by $24 \%$ for every 1 year increase in age, $\mathrm{p}=0.013$; Table 2 . In sensitivity analyses, where we included all the LTFU patients as having died, we found no significant change in our overall outcomes.

\begin{tabular}{|c|c|c|c|c|}
\hline \multirow[t]{2}{*}{ Characteristics } & \multicolumn{2}{|l|}{ Bivariate analysis } & \multicolumn{2}{|c|}{ Multivariate analysis } \\
\hline & $\begin{array}{l}\text { Crude HR } \\
(95 \% \mathrm{Cl})\end{array}$ & $\begin{array}{l}P \\
\text { value }\end{array}$ & $\begin{array}{l}\text { Adjusted HR } \\
(95 \% \mathrm{Cl})\end{array}$ & $\begin{array}{l}P \\
\text { value }\end{array}$ \\
\hline \multicolumn{5}{|l|}{ Age (years) } \\
\hline Per 1 yr increase & $0.7(0.64-0.91)$ & 0.003 & $0.76(0.62-0.94)$ & 0.01 \\
\hline$>5.0$ & 1.00 (Ref) & - & & \\
\hline$<5.0$ & $3.45(1.20,9.94)$ & 0.02 & & \\
\hline \multicolumn{5}{|l|}{ Sex } \\
\hline Female & 1.00 (Ref) & & & \\
\hline Male & $2.42(1.07,5.50)$ & 0.03 & & \\
\hline \multicolumn{5}{|l|}{ Pulmonary TB } \\
\hline No & 1.00 (Ref) & & & \\
\hline Yes & $2.16(0.75,6.22)$ & 0.15 & & \\
\hline \multicolumn{5}{|c|}{ Cotrimoxazole prophylaxis } \\
\hline Yes & 1.00 (Ref) & - & & \\
\hline No & $0.78(0.27,2.26)$ & 0.65 & & \\
\hline \multicolumn{5}{|l|}{ Thrush } \\
\hline No & 1.00 (Ref) & - & & \\
\hline Yes & $2.23(0.53,9.34)$ & 0.28 & & \\
\hline \multicolumn{5}{|c|}{ WHO clinical Stage } \\
\hline 1 or 2 & 100 (Ref) & - & & \\
\hline 3 or 4 & $1.58(0.74,3.37)$ & 0.24 & & \\
\hline \multicolumn{5}{|c|}{ Weight-for-age Z score } \\
\hline$>-3.0$ & 1.00 (Ref) & - & & \\
\hline$<-3.0$ & $2.11(1.0,4.5)$ & 0.05 & & \\
\hline globin lev & & & & \\
\hline
\end{tabular}




\begin{tabular}{|l|l|l|l|l|}
\hline$<8 \mathrm{~g} / \mathrm{dL}$ & 1.00 (Ref) & - & & \\
\hline$>8 \mathrm{~g} / \mathrm{DI}$ & $1.58(0.37,6.74)$ & 0.53 & & \\
\hline
\end{tabular}

Severe immunodeficiency

\begin{tabular}{|l|l|l|l|l|}
\hline No & $1.00($ Ref) & - & & \\
\hline Yes & $1.92(0.83,4.44)$ & 0.13 & & \\
\hline
\end{tabular}

Table 2: Predictors of mortality in HIV-1 infected children initiated on ART between 2005-2013 at the Jos University Teaching Hospital.

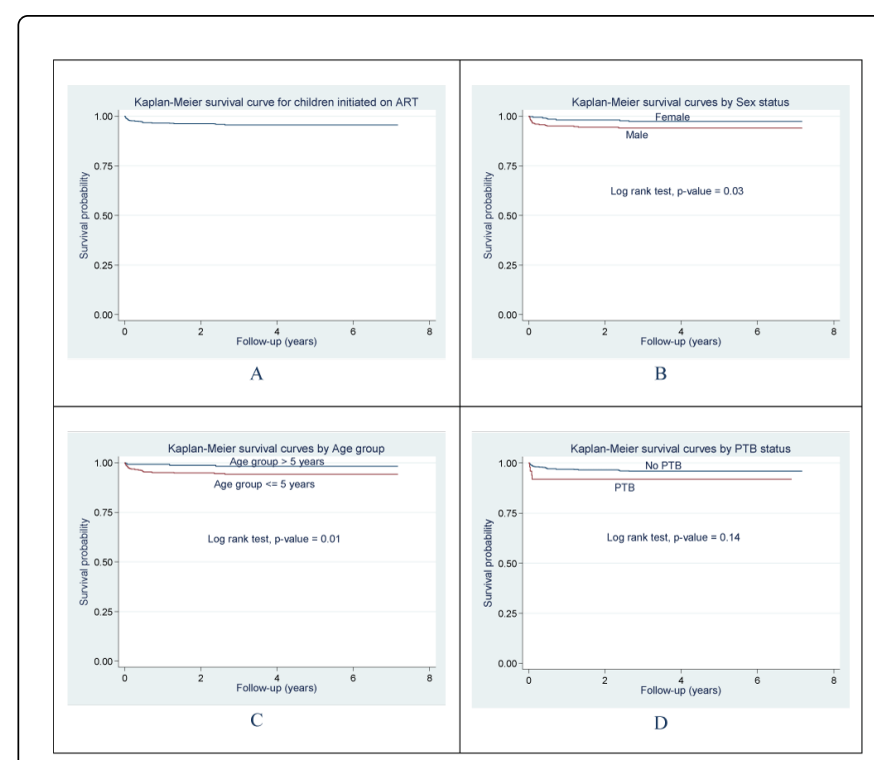

Figure 1: Survival following diagnosis and initiation of ART. Kaplan Meier survival curves: plot A shows the survival probability for the cohort of children while plots B, C and D show unadjusted associations between Sex, Age group and PTB with mortality risk after initiation of ART.

\section{Discussion}

The mortality rate in this study among HIV-1 infected children initiated on ART was 1.0 per 100 child-years and the main predictor of mortality was age.

This mortality rate was low compared to the rates of 4.0, 4.7 and 8.4 per 100 child-years reported in Ethiopia [4], South Africa [5] and Kenya [3] respectively. The lower mortality rate may be due to the higher baseline median absolute CD4+ cell count $(480$ cells/ $\mu \mathrm{l})$ at ART initiation and a lower proportion (41.0\%) of children with severe immunodeficiency in our study cohort as compared to those found in the South African (CD4 count: 226 cells/ $\mu$ l; 47.7\% severe immunodeficiency) and Kenyan studies (CD4 count: 286 cells/ $\mu$; $89 \%$ severe immunodeficiency), respectively [3,5]. In our study, we analyzed data from 2005-2013, where all HIV-infected children $<24$ months of age enrolled during 2010-2013, irrespective of their CD4 ${ }^{+}$ cell count or CD4\% levels, were initiated on ART (in compliance with the Nigeria 2010 guidelines), whereas the South African study (analyzed data from 2002-2008) where the mortality rate was 4.7 per 100 child-years, children $<18$ months were commenced at CD $4 \%$ of
$<20 \%$ based on the South African 2004 guidelines. Newer and current guidelines recommend initiating $\mathrm{ART}$ at much higher $\mathrm{CD} 4^{+}$cell counts or CD4\% levels. Low baseline $\mathrm{CD}^{+}$levels or severe immunodeficiency has been previously associated with increased mortality [3-6], which could be attributed to the associated comorbidity from OIs like PTB and life-threatening bacterial infections [22-24].

Another explanation for our study's low mortality rate may be the high proportion $(83.1 \%)$ of children that were on CTX prophylaxis as compared to the $52.3 \%$ in the Ethiopian study [4]. A large doubleblind, randomized placebo-controlled trial from Zambia demonstrated the benefits of CTX prophylaxis in reducing morbidity and mortality in HIV-infected children regardless of $\mathrm{CD}^{+}$levels at baseline [22]. The small proportion of children with severe malnutrition $(21.3 \%)$ and PTB (7.4\%) at baseline, in our study cohort may also explain the low mortality rate in our patient cohort, as these co-morbid conditions are also associated with increased mortality in children.

The low mortality rate of 1.0 per 100 child-years found in our study was close to the figure of 2.0 reported in the United Kingdom in 2001-2002 [13]. This may suggest that the level of care provided by our pediatric HIV clinic was of a fairly good standard, perhaps comparable to that of RRC. Our clinic is well-staffed with pediatricians, nurses, laboratory scientists, and other health care workers that were welltrained in the management and care of children with HIV. The staff provided regular counseling and caregiver/patient education that are critical for the supportive care of HIV-infected children. The role the good standard of care could have played with respect to the issue of a lower mortality in our setting was also reflected in the low nonadherence rate of $5.8 \%$ for ART we have observed in a recent study [25]. In addition, our laboratory services are of high standard and provide the needed results on time to enhance patient management.

We found age as the main predictor of death, with mortality decreasing by $24 \%$ for every 1 year increase in age; with the risk of dying being about three and half times more in children $<5$ years compared to those $>5$ years and the IQR of their ages was 0.6-3.6 years. This finding was similar to that of Bolton-Moore et al. in Zambia [6], where the median age of children on ART who died was 46 months (3.8 years). They also observed that among younger children $(<5$ years), mortality was associated with lower WAZ score. This observation was also similar to ours, as we noted that majority $(83.3 \%)$ of our patients $<5$ years of age who died also had severe malnutrition (WAZ $<-3$ ). Severe malnutrition could have contributed to the increased mortality in this age group. In RLC, severe malnutrition is a well-recognized cause of mortality in those aged $<5$ years. Additionally, the majority of our patients $<5$ years who died also had PTB (100\%) and severe immunodeficiency (93.8\%), which also potentially contributed to the increased mortality in this group.

Our finding in multivariable Cox modeling that sex does not predict mortality, contrasts with that of Zanoni et al., who reported that female gender was associated with increased mortality in HIV infected children initiated on ART in South Africa [5] and that of another North American study where mortality rate was higher in female children [26]. Zanoni et al. concluded that it was unclear whether this disparity was attributable to intrinsic biological differences between the sexes or social differences such as delayed presentation for care, differences in parental supervision of boys and girls, or devaluation of the female gender that could place females at a higher risk of mortality after ART initiation in South Africa [5]. We were unable to corroborate their findings in our analyses. 
In our study, the proportion of those who died was higher than that of survivors ( $37.5 \%$ vs. $11.1 \%)$ in the age group $<1$ year (infants) as compared to the other age groups. It has previously been reported that infant mortality is higher in boys than girls in most parts of the world [27-29] and this has been explained by gender differences in genetic and biological makeup. Our observation that mortality in children under 5 years of age was higher than the other age groups combined with the higher mortality in males (66.7\%) than females $(33.3 \%)$ is consistent with the findings of Sawyer et al. that on average, boys' under-five mortality in the 2000 s was about $2 \%$ higher than girls' in less developed regions like Africa [28].

Previous studies in RLC have found an association between severe immunodeficiency and mortality [4,7]. The reason that severe immunodeficiency is usually associated with higher mortality is because of the associated co-morbidities, such as PTB and lifethreatening bacterial infections $[23,24]$ as well as severe malnutrition. Severe malnutrition in children usually results in marked depression of both cell-mediated and humoral immunity reducing their ability to cope with life-threatening infections [30,31]. In our study, though severe malnutrition was not an independent predictor of mortality in the multivariate Cox regression modeling, it was associated with mortality in the bivariate modeling. The presence of severe immunodeficiency is usually considered an indicator of late presentation for health care, resulting in late HIV diagnosis and treatment [32-35] which could lead to poorer outcomes [6,36].

A limitation of this study was that, the low mortality rate we reported may be an underestimate. It is possible that of the $53(5.6 \%)$ children that were LTFU some may have died; had they been included in the analysis, the mortality rate may have been higher. However, this was unlikely because a sensitivity analysis considering all LTFU as dead yielded a similar rate of 0.97 per 100 child-years of follow-up (95\% CI, 0.67-1.40).

Another limitation could be the sample size used for our analysis, which may not have being adequate. This was suggested by the strong association with non-significant $p$-values that we saw between some of the predictor variables and mortality in the bivariate Cox regression analysis. Finally, another limitation were missing values for some variables used in the regression analyses; while missing data are noteworthy, we suspect that the impact should be minimal given that no more than $10 \%$ of values were missing for any given predictor (except in the case of viral load, which we therefore, we did not use in the multivariate modeling).

\section{Conclusion}

The lower mortality rate for our study suggests that even in RLC, mortality rates could be reduced given a good standard of care. Early initiation of ART in younger children with close monitoring during follow-up could further reduce mortality.

\section{Acknowledgement}

This publication was facilitated, in part, by the US Department of Health and Human Services, Health Resources and Services Administration (U51HA02522- 01-01) which funded HIV/AIDS treatment and care services at APIN, JUTH, Jos.

Data analysis and writing of this paper was supported by the Medical Education Partnership Initiative in Nigeria (MEPIN) project funded by Fogarty International Center, the Office of AIDS Research, and the National Human Genome Research Institute of the National Institute of Health, The Health Resources and Services Administration (HRSA) and the Office of the US Global AIDS Coordinator under Award Number R24TW008878.

The content is solely the responsibility of the authors and does not necessarily represent the official views of the funding organizations.

We thank APIN, JUTH for permission to use the patients' Data.

\section{References}

1. UNAIDS (2013) UNAIDS AIDS report on Global AIDS epidemic.

2. UNAIDS (2012) Regional fact sheet Sub-Saharan Africa.

3. Wamalwa DC, Obimbo EM, Farquhar C, Richardson BA, Mbori-Ngacha DA, et al. (2010) Predictors of mortality in HIV-1 infected children on antiretroviral therapy in Kenya: a prospective cohort. BMC Pediatr 10: 33.

4. Koye DN, Ayele TA, Zeleke BM (2012) Predictors of mortality among children on Antiretroviral Therapy at a referral hospital, Northwest Ethiopia: a retrospective follow up study. See comment in PubMed Commons below BMC Pediatr 12: 161.

5. Zanoni BC, Phungula T, Zanoni HM, France H, Feeney ME (2011) Risk Factors Associated with Increased Mortality among HIV Infected Children Initiating Antiretroviral Therapy (ART) in South Africa. PLoS ONE 6: e22706.

6. Bolton-Moore C, Mubiana-Mbewe M, Cantrell RA, Chintu N, Stringer EM, et al. (2007) Clinical outcomes and CD4 cell response in children receiving antiretroviral therapy at primary health care facilities in Zambia. JAMA 298: 1888-1899.

7. Bong CN, Yu JK, Chiang HC, Huang WL, Hsieh TC, et al. (2007) Risk factors for early mortality in children on adult fixed-dose combination antiretroviral treatment in a central hospital in Malawi. AIDS 21: 1805-1810.

8. Reddi A, Leeper SC, Grobler AC, Geddes R, France KH, et al. (2007) Preliminary outcomes of a paediatric highly active antiretroviral therapy cohort from KwaZulu-Natal, South Africa. BMC Pediatr 7: 13.

9. Rouet F, Fassinou P, Inwoley A, Anaky MF, Kouakoussui A, et al. (2006) Long-term survival and immuno-virological response of African HIV-1infected children to highly active antiretroviral therapy regimens. AIDS 20: 2315-2319.

10. Sutcliffe CG, van Dijk JH, Munsanje B, Hamangaba F, Siniwymaanzi P, et al. (2011) Risk factors for pre-treatment mortality among HIV-infected children in rural Zambia: a cohort study. PLoS One 6: e29294.

11. Viani RM, Araneta MR, Deville JG, Spector SA (2004) Decrease in hospitalization and mortality rates among children with perinatally acquired HIV type 1 infection receiving highly active antiretroviral therapy. Clin Infect Dis 39: 725-731.

12. Gortmaker SL, Hughes M, Cervia J, Brady M, Johnson GM, et al. (2001) Effect of combination therapy including protease inhibitors on mortality among children and adolescents infected with HIV-1. N Engl J Med 345: 1522-1528.

13. Gibb DM, Duong T, Tookey PA, Sharland M, Tudor-Williams G, et al. (2003) Decline in mortality, AIDS, and hospital admissions in perinatally HIV-1 infected children in the United Kingdom and Ireland. BMJ 327: 1019.

14. Peacock-Villada E, Richardson BA, John-Stewart GC (2011) PostHAART outcomes in pediatric populations: comparison of resourcelimited and developed countries. Pediatrics 127: e423-441.

15. Nigeria (2006) Population and Housing Census (2010) Population Distribution by Sex, State, LGA and Senatorial District. National Population Commission of Abuja.

16. Federal Ministry of Health (2010) Nigeria: National Guidelines for Paediatric HIV and AIDS Treatment and Care.

17. Federal Ministry of Health (2010) National Tuberculosis and Leprosy Control Programme- Workers Manual. 
Citation: Ebonyi AO, Oguche S, Meloni ST, Sagay SA, Kyriacou DN, et al. (2014) Predictors of Mortality in a Clinic Cohort of HIV-1 Infected Children Initiated on Antiretroviral Therapy in Jos, Nigeria. J AIDS Clin Res 5: 403. doi:0.4172/2155-6113.1000403

Page 7 of 7

18. WHO (2013) Application tools: WHO AnthroPlus software.

19. WHO. Global Database on child growth and malnutrition.

20. WHO (2010) Antiretroviral therapy of HIV infection in infants and children: Towards universal access. Recommendations for a public health approach.

21. WHO (2001) Iron deficiency anaemia: assessment, prevention and control. A guide for program managers.

22. Chintu C, Bhat GJ, Walker AS, Mulenga V, Sinyinza F, et al. (2004) Cotrimoxazole as prophylaxis against opportunistic infections in HIVinfected Zambian children (CHAP): a double-blind randomised placebocontrolled trial. Lancet 364: 1865-1871.

23. Grant AD, Djomand G, Smets P, Kadio A, Coulibaly M, et al. (1997) Profound immunosuppression across the spectrum of opportunistic disease among hospitalized HIV-infected adults in Abidjan, Côte d'Ivoire. AIDS 11: 1357-1364.

24. Lawn SD, Harries AD, Anglaret X, Myer L, Wood R (2008) Early mortality among adults accessing antiretroviral treatment programmes in sub-Saharan Africa. AIDS 22: 1897-908.

25. Ebonyi AO, Toma BO, Ejeliogu EU, Ugoagwu PO, Anejo-Okopi JA, et al. (2014) Nonadherence to first-line antiretroviral therapy among human immunodeficiency virus1 infected children at the Jos University Teaching Hospital, Jos, Nigeria. J Med Trop 16: 66-70.

26. Foca M, Moye J, Chu C, Matthews Y, Rich K, et al. (2006) Gender differences in lymphocyte populations, plasma HIV RNA levels, and disease progression in a cohort of children born to women infected with HIV. Pediatrics 118: 146-155.

27. Waldron I (1998) Sex differences in infant and early childhood mortality: major causes of death and possible biological causes. New York, USA. 64-83.
28. Sawyer CC (2012) Child Mortality Estimation: Estimating Sex Differences in Childhood Mortality since the 1970s. PLoS Med 9: e1001287.

29. Pongou R (2013) Why is infant mortality higher in boys than in girls? A new hypothesis based on preconception environment and evidence from a large sample of twins. Demography 50: 421-444.

30. Najera O, Gonzalez, Toledo, López L, Ortiz R (2004) Flow cytometry study of lymphocytes in malnourished and well-nourished children with bacterial infections. Clin Diagn Lab Immunol 11: 577-580.

31. NajeraO, Gonzalez, Cortes E, Toledo G, Ortiz R (2007) Effector T lymphocytes in wellnourished and malnourished infected children. Clin Exp Immunol 148: 501-506.

32. Antinori A, Coenen T, Costagiola D, Dedes N, Ellefson M, et al. (2011) Late presentation of HIV infection: a consensus definition. HIV Med 12: 61-64.

33. Wolbers M, Bucher HC, Furrer H, Rickenbach M, Cavassini M, et al. (2008) Delayed diagnosis of HIV infection and late initiation of antiretroviral therapy in the Swiss HIV Cohort Study. HIV Med 9: 397-405.

34. Louis C, Ivers LC, Smith Fawz MC, Freedberg KA, Castro A (2007) Late presentation for HIV care in central Haiti: factors limiting access to care. AIDS Care 19: 487-491.

35. Sabin CA, Smith CJ, Gumley H, Murphy G, Lampe FC, et al. (2004) Late presenters in the era of highly active antiretroviral therapy: uptake of and responses to antiretroviral therapy. AIDS 18: 2145-2151.

36. Sauvageot D, Schaefer M, Olson D, Pujades-Rodriguez M, O'Brien DP (2010) Antiretroviral Therapy Outcomes in Resource-Limited Settings for HIV-Infected Children <5 Years of Age. Pediatrics 125: e1039. 